\title{
Yaşlı bireylerin çocukluk dönemlerindeki oyun pratikleri ile günümüz çocuklarının oyun pratiklerinin karşılaştırılması ${ }^{1,2}$
}

\author{
Sergender SEZER ${ }^{3}$ \& Tule GÜLTEKİN \\ Muğla Sıtkı Koçman Üniversitesi, Edebiyat Fakültesi, Sosyoloji Bölümü, Muğla / Türkiye \\ İstanbul Üniversitesi-Cerrahpaşa, Sağlık Bilimleri Fakültesi, Gerontoloji Bölümü, İstanbul / Türkiye
} ORCID ID: 0000-0002-7097-8691 - ORCID ID: 0000-0002-9531-7187

\begin{abstract}
ÖZET
Bu çalışmada modernleşmenin ve teknolojik gelişmelerin etkilediği toplumsal değişmenin çocuk oyunlarına ve oyun pratiklerindeki değişime nasıl yansıdığı belirlenmeye çalışılmıștır. Araştırma, çocukluk döneminde toplumsallaşmaya büyük etkisi olduğu kabul edilen çocuk oyunlarının da geçmișten bugüne büyük değişiklikler gösterdiği bilinmektedir. Bu nedenle araştırmanın temel problemini, yaşlı bireylerin çocukluk dönemindeki oyun pratikleri ile günümüz çocuklarının oyun patiklerinin nasıl ve neden değişiklik gösterdiği olușturmaktadır. Bu kapsamda araştırma Muğgla ilinin Yeniköy Mahallesi'nde gerçekleştirilmiștir. Tek mahallenin seçilmiş olmasının amacı, aynı mekânda büyümüş ve büyümekte olan bireyler arasında karş̧laştırma yaparak kültürel aktarımın ve değişimin nasıl ilerlediğini görmektir. Yeniköy'de doğup büyüyen ve yaşayan sekiz yaşlı ve sekiz çocuk olmak üzere toplam da on altı katılımcıyla derinlemesine görüşme yapılmıştır. Araștırma kapsamında elde edilen veriler yorumlayıcı anlayıcı yöntem ve içerik analizi tekniği kullanılarak analiz edilmiştir. Bunun yanında araştırmada kota ve kartopu örneklem kullanılmıştır. Araştırmanın sonucuna bakıldığında; toplumsal değişmeye paralel olarak oyun kültürünün geleneksel oyun kültüründen modern oyun kültürüne doğru evrildiği, fakat bu evrim sürecinin hala devam etmekte olduğu görülmektedir.
\end{abstract}

\section{MAKALE GEÇMIŞİ}

Geliş 11 Mayıs 2020

Kabul 29 Eylül 2020

\section{ANAHTAR KELIMELER}

Yaşl, toplumsal değişme, oyun, oyun kültürü

\section{Comparison of the play practices of children with older adult individuals and the play practices of children}

\section{ABSTRACT}

In this study, it was tried to determine how social change influenced by modernization and technological developments reflected on children's plays and changes in play practices. In the research, it is known that children's plays, which are considered to have a great impact on socialization in the childhood, also showed great changes from past to present. For this reason, the main problem of the research is the play practices of elderly individuals in childhood, and how and why the play booties of today's children vary. In this context, the research was carried out in Yeniköy District of Muğla province. The purpose of choosing a single neighborhood is to see how cultural transfer and change are progressing by making comparisons between individuals who have grown and grew up in the same space. In-depth interviews were made with a total of sixteen participants, eight elderly and eight children, who were born and grew up in Yeniköy. The data obtained within the scope of the research were analyzed using the interpretative understanding method and content analysis technique. In addition, quota and snowball sampling were used in the research. Looking at the result of the research; In parallel with social change, it is seen that play culture has evolved from traditional play culture to modern play culture, but this evolutionary process is still ongoing.

\section{ARTICLE HISTORY}

Received 11 May 2020

Accepted 29 September 2020

\section{KEYWORDS}

Older adult, social change, play, play culture

1Bu makale, 19-21 Eylül 2019 tarihinde Ankara'da düzenlenen IX. Ulusal Sosyoloji Kongresi'nde sözlü bildiri olarak sunulmuş metnin geliştirilmiş ve düzenlenmiş halidir.

${ }^{2}$ Makalenin Kaynak Olarak Gösterimi: Sezer, S., \& Gültekin, T. (2020). Yaşlı bireylerin çocukluk dönemlerindeki oyun pratikleri ile günümüz çocuklarının oyun pratiklerinin karşılaştırılması. Yaşlı Sorunları Araştırma Dergisi (YSAD), 13(2), 65-71. doi:10.46414/yasad.735773

3Sorumlu Yazar E-mail: sergender@mu.edu.tr

YSAD-EIRJ 2020 / 13(2), 65-71 


\section{GíRİs}

Oyun doğadaki tüm hayvan türleri için türün genel davranıșlarını taklit etme, öğrenme, avlanma, işbirliğinin öğrenildiği amaçlı ve vazgeçilmez bir etkinlik olarak gözlemlenmektedir. İnsan da doğanın bir parçasıdır ve oyun insan yavruları için de önemli bir gelișimsel öğrenme sürecidir. Toplumsal değişme, köklü kültürel değișimler, çocukların oyun kültürünü etkilemekte ve bu da araştırmacıları oyun kültürünün değişimini sosyo-kültürel açıdan ele almaya itmektedir. Çünkü oyun, kültürden kültüre, toplumdan topluma değişiklik gösteren bir pratiktir. Geleneklerden, inançlardan, efsanelerden, iklimden, coğrafi özelliklerden, ekonomiden, teknolojik gelişmelerden, cinsiyet ve sosyal sinıflardan etkilenmektedir. $\mathrm{Bu}$ da oyun pratiklerinin ekonomik, sosyal, kültürel ve teknolojik bağlamda ele alınmasını gerektirmektedir.

Oyun, toplumsallaşmanın, toplumsal birey olmanın, öğrenmenin, psikolojik, bedensel-ruhsal gelişmenin ve rahatlamanın, bașkalarının haklarına saygı duymanın, paylașmanın, ișbirliğinin, uzlașmanın öğrenildiği önemli aktivitelerden biri olarak kabul edilmektedir. Toplumsal değişmeye paralel olarak çocukların oyunlarında da değişiklikler meydana gelmektedir. Bu araştırmada modernleşme süreçlerinin getirmiş olduğu toplumsal değişmenin ve dönüșümün etkisiyle çocukluk döneminde toplumsallaşma üzerinde önemli etkisi olan oyunların değişimi belirlenmeye çalıșılmıștır. $\mathrm{Bu}$ nedenle araștırmanın temel problemini, yaşlı bireylerin çocukluk dönemindeki oyun pratikleri ile cocukların günümüzdeki oyun patiklerinin nasıl değişiklik gösterdiği olușturmaktadır.

\subsection{0yun ve oyunların sinıflandirılmas}

Oyun yüzyıllardır üzerinde çeșitli bilim alanlarından çalışmalar yapılmakta olan bir olgudur. Bu sebeple oyun tanımlamaları araștırmacıların çalıșma alanlarının etkisiyle birlikte farklılaşma göstermektedir. Örneğin; Erikson'a göre oyun, çocuğun yenilgiler, acılar ve yaşamda karşılaşılan hayal kırıklıklarına kendini hazırlamak için kullandığı bir araçtır (Arslan, 2000: 41). Bunun yanında Freud, oyunu; çocukların sosyal olarak olgunluğa ulaşmalarında ve kendi öz benliklerini bulmalarında yardımcı olan bir etkinlik olarak tanımlamaktadır ve ona göre oyun, çocuğun davranıșının ve kișiliğinin bir aynasıdır. Piaget için; oyun ile bilişsel gelişim arasında bir yakınlık vardır ve bu yakınlık daha çok oyunu düșünme evresinin bir ürünü olarak görmektedir (Cinel, 2006: 12).

Oyunlar yukarıda ifade edildiği gibi birçok farklı bakış açısıyla ele alınmıştır. Tıpkı tanımlamalar gibi oyunların sınıflandırılması üzerinde de pek çok ayrı görüş bulunmaktadır. Fakat bu çalışma kapsamında oyunlar takım oyunları, arkadașla ile oynana oyunlar, bireysel oyunlar ve dijital oyunlar olarak ele alınmıștır.

Arkadaş ile oynanan oyunlar: Çocukların kalabalık gruplar halinde gruplarla kısa veya uzun sürelerle oynadıkları oyunlardır. Çocuğun diğer çocuklarla bir șeyleri paylașması ve beraber bașarma duygusu ön plana çıkar (Şahinkaya, 2008: 7-8).

Bireysel oyunlar: Bireysel oyunlar bu çalışma kapsamında çocukların tek başlarına oynadıkları oyunlar olarak tanımlanmıștır.

Dijital oyunlar: İletişim ve eğitim amacıyla kullanılan bilgisayar, teknolojinin gelişmesiyle birlikte yaygın olarak eğlence amaçlı olarak da kullanılmaya başlanmıștır. Özellikle günümüzde çocuklar ve gençler arasında yaygın bir kullanıma sahiptir. Bilgisayar oyunları gençlerin ve çocukların koordinasyon, dikkat toplama ve sorun çözme yeteneklerini geliștirmektedir. Fakat bunun yanında uzun süreli zaman geçirme sebebiyle kas ve iskelet sistemi hastalıkları, oyunların türüne göre saldırgan veya içe kapanma gibi davranıș değișikliklerine sebep olabilmektedir (Akçay \& Özcebe, 2012: 67). Bilgisayarın yanında telefon ve joy-stick gibi cihazlarda dijital oyunlar kapsamına alınmaktadır.

Oyun kültürü olarak incelendiğinde literatürde geleneksel, modern ve post-modern kültür olarak üç farklı sınıflandırma olduğu görülmektedir. $\mathrm{Bu}$ üç kültürün ayrımına ve özelliklerine bakılarak așağıdaki tablo oluşturulmuştur (Sormaz, 2010: 110-119).

Tablo 1. Oyun kültürleri ve özellikleri

\begin{tabular}{|c|c|c|c|}
\hline & Geleneksel & Modern & Post-Modern \\
\hline 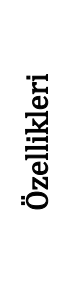 & $\begin{array}{l}\text { - Daha çok grup oyunu } \\
\text { - Oyunların daha çok açık } \\
\text { alanlarda oynanması } \\
\text { - Çoğu oyunun hareket içeren } \\
\text { oyun olması } \\
\text { - Oyun arkadaşlıklarının yakın } \\
\text { olması }\end{array}$ & $\begin{array}{l}\text { - Daha az grup oyunu } \\
\text { - Oyunların genellikle iç mekanda } \\
\text { olması } \\
\text { - Diğer çocuklarla daha az } \\
\text { iletişim }\end{array}$ & $\begin{array}{l}\text { - Sosyal oyunların yok oluşu ve } \\
\text { bireyselleşme } \\
\text { - Oyunun tamamen iç mekânlara } \\
\text { taşınması } \\
\text { - Bilgisayar ve internet } \\
\text { oyunlarının yaygınlaşması }\end{array}$ \\
\hline
\end{tabular}




\subsection{0yunun bireylerin gelişimine etkisi}

Oyun, "toplumsal gerçekliğin taklidi" niteliği taşır. Çocuk bu taklit etkinliğini, kendi etkinliğiyle dönüştürebilir ve zaten toplumsallaşmayı sağlayan da, bu dönüştürebilme yeteneğidir. Bu nedenle de, bir çocuğun herhangi bir oyuna yaklaşım biçimi, seçtiği ve önem verdiği oyunlar, çocuğun çevresine olan tavrını, çevresiyle olan ilişkilerini ve başkaları ile kendisi arasında nasıl bir bağlantı kurmuş olduğunu göstermektedir (Uluğ, 2007: 149).

Oyunlar çocukların "kendi kurguladıkları bir sosyal hayat" olması bakımından önemlidir. Çünkü toplumsallaşma için dramatize etme, deneyimleme ve içselleștirme gerekir. Oyun toplumsal davranışların ortaya çıkarılması için bir araçtır ve çocuğun toplumsal yönden gelişmesinde oyunun büyük bir rolü vardır. İşte bu noktada oyunlar, ileriye dönük toplumsallaştırma işlevi görmektedirler.

Bireyler oyunla birlikte fiziksel, duygusal ve bilișsel yönden gelişimlerine farkında olarak veya olmayarak katkıda bulunurlar. Fiziksel gelișim; Oyun sırasında bazı hareketlerin tekrarlanması çocuğun kas gelişimini hızlandıracaktır. Duygusal olarak ise; çocuk oyun yoluyla mutluluk, sevinç, acıma, korku, kaygı, güven duyma, bağımlılık, ayrılık gibi birçok duygusal tepkiyi öğrenirken aynı zamanda bazı duygusal tepkilerini kontrol etmeyi öğrenir. Son olarak oyunlar çocukların bilișsel gelişimlerine katkı sağlarlar. Bellekte tutma, hatırlama, isimlendirme, sınıflandırma, analiz, sentez, problem çözme gibi zihinsel süreçlerin işleyişi oyunla hızlanmakta ve gelişmektedir. Mantık yürütmeyi, sebep-sonuç ilişkileri kurmayı, dikkatini toplamayı, kendini bir amaca yöneltmeyi, oyunda ortaya çıkan sorunları görmeyi ve bunlara çözümler bulmayı öğrenmektedir (Akınbay, 2014: 9-12).

\section{MATERYAL VE YÖNTEM}

Araștırma Muğla İli merkez Menteșe İlçesi Yeniköy Mahallesi'nde gerçekleştirilmiştir. Yeniköy Mahallesi; hem yaşlı bireylerin hem de çocukların kolay ulaşılabilir olması ve ulaşımın kolaylığı sebebiyle örneklem kapsamına alınmıştır. Bunun dışında Muğla Sıtkı Koçman Üniversitesi'nin içinde olduğu Kötekli Mahallesi'sine en yakın, doğayla iç içe ve kısman de olsa köy özelliğini koruyan bir mahalledir. Kötekli Mahallesi'nde arsa ve konut fiyatlarının, kiraların aşırı yükselmesinden sonra yatırımcıların ve öğrencilerin yeni gözdesi olmuş bir mahalledir. $\mathrm{Bu}$ durum Yeniköy'deki köy görünümünü değiștirip hızla șehir görünümüne geçmesinde en önemli etken olmuştur. Ayrıca tek mahallenin seçilmiş olmasının amacı, tek bir mekanda büyümüş ve büyümekte olan bireyler arasında karşılaştırma yaparak kültürel aktarımın ve değişimin nasıl ilerlediğini görmektir. Bu nedenle dişarıdan göç almış olmasına rağmen örneklem Yeniköy doğumlu ve orada ikamet eden yaşlı ve çocuklardan seçilmiştir.

Weber'e göre eyleme bağlanan anlamı, hem pratik bilgiler ile hem de açıllayıcı anlayış ile kavramak gerekir. Yani, toplumsal eylemin açıklaması; bireylerin eylemlerine verdikleri öznel anlamın ve bu eylem ile anlam arasındaki bağlantının kurulması ile mümkündür (Tolan, 2005: 36). Çünkü, Weber'e göre sosyoloji, eylemin sürecini ve sonuçlarını nedensel olarak açıklayabilmek için eylemi yorumlayıp anlayan bir bilim olarak tanımlanmaktadır (Çelebi, 2007: 170). $\mathrm{Bu}$ nedenle eylemler yalnızca sonuçları çerçevesinde ele alınmayıp nedensellik bağlamında analiz edilmelidir. Çalışmada içerik analizinin kullanılmasının amacı ise; konu hakkında betimleyici bulgulara ulașmak ve bu bulguların anlamlı ve sistematik hale gelmesine yardımcı olacak temaları ortaya çıkarmaktır (Büyüköztürk, Kılıç Çakmak, Akgün, Karadeniz \& Demirel, 2014: 247). Bu doğrultuda araştırmada elde edilen verilerin sosyolojik analizleri yapılırken yorumlayıcı anlayıcı yöntem ve içerik analizi tekniği kullanılmıştır.

\section{BULGULAR}

Araştırma Muğla'nın Menteșe ilçesine bağlı Yeniköy mahallesinde gerçekleştirilmiştir. 16 katılımcıyla derinlemesine görüşme yapılmıştır. Görüşmeler doğrultusunda aşağıda yer alan tablolar oluşturulmuştur. $\mathrm{Bu}$ tablolarda görüşmecilere ait bilgilere ve görüşmenin özetlerine ulaşabilmek mümkündür.

Araştırma örnekleminin verdiği bilgilere genel olarak bakıldığında; yukarıda tablo 1'deki görünüme benzer bir durumun ortaya çıtığını söylemek mümkündür. Mahalle köy halinde ve daha geleneksel bir yapısı söz konusuyken son 10-15 ylda üniversite sayesinde bir mahalleye dönüşerek kentsel özellikler göstermeye başlamıştır. Bu değişim süreci, Türkiye'nin genel toplumsal değişme ve teknolojik gelişmelerle birlikte çocukların oyunlarını da değiștirmeye başlamıştır. Bugün postmodern bir görüntü henüz oluşmuş olmasa da modern bir görüntü oluşmuş denilebilir.

Geleneksel yapıda çocukların oyunları daha grup şeklinde ve doğayla iç içe, diş mekanlarda oynanan oyunlar iken bugün daha bireysel, kapalı mekanlarda, hazır oyuncaklara ve bilgisayar oyunlarına doğru evrilmiştir. Bunun önemli sebeplerinden biri, kentleşmeyle birlikte, ebeveynlerin kente özgü mal ve hizmet üretiminde çalışıyor olmaları ve buna bağlı olarak çocuklarla ilgili duyulan güvenlik kaygılarıdır.

Oysa günümüz toplumunda ebeveynler çocuklarıyla daha fazla zaman geçirmek, oyunlar oynamak eğilimindedirler. Bunun da iki önemli sebebi bulunmaktadır; birincisi, ebeveynlerin çocuklarıyla oyun oynamasının, zaman geçirmesinin çocukların gelişimine olumlu katkı sağlıyor olması konusundaki bilinçlenme, ikincisi ise, kentleşme ile birlikte hem az çocuk yapma eğiliminin artması hem de çocukların dışarıya yeterince çıkamadıkları için oyun arkadaşı bulmakta zorlanmalarıdır. Katılımcılardan Ç1 "kardeşim, annem babamla saklambaç oynuyorum. En çok ebe annem oluyor" diyerek oyun arkadaşlarının aynı zamanda ebeveynleri olduğunu belirtmiștir. 
Tablo 2. Görüşmelerin özeti - yaşlı bireyler

\begin{tabular}{|c|c|c|c|c|c|c|c|c|}
\hline Değişken & $\mathrm{K} 1$ & E1 & $\mathrm{K} 2$ & E2 & K3 & E3 & K4 & E4 \\
\hline Cinsiyet & Kadın & Erkek & Kadın & Erkek & Kadın & Erkek & Kadın & Erkek \\
\hline Yaş & 72 & 82 & 78 & 70 & 84 & 76 & 87 & 68 \\
\hline Eğitim & $\begin{array}{l}\text { Okuryazar } \\
\text { Değil }\end{array}$ & $\begin{array}{c}\text { İlkokul Terk } \\
\text { (Sadece } \\
\text { Okuryazar) } \\
\end{array}$ & İlkokul & İlkokul & İlkokul üçe kadar & İlkokul & Oku-yazar & Ortaokul \\
\hline Oyun Yeri & $\begin{array}{l}\text { Sokak, } \\
\text { Tarla, } \\
\text { Bahçe }\end{array}$ & $\begin{array}{l}\text { Sokak, Köy } \\
\text { Meydanı, } \\
\text { Tarla }\end{array}$ & Sokak, Bahçe, Ev & $\begin{array}{l}\text { Sokak, Köy } \\
\text { Meydanı }\end{array}$ & Tarla, Bahçe, Ev & $\begin{array}{c}\text { Sokak, Köy } \\
\text { Meydanı, Tarla, } \\
\text { Ev, Okul }\end{array}$ & Sokak, Bahçe, Ev & $\begin{array}{c}\text { Sokak, Köy Meydanı, } \\
\text { Ev, Okul }\end{array}$ \\
\hline Oyun Türü & $\begin{array}{l}\text { Arkadaş } \\
\text { Oyunları }\end{array}$ & $\begin{array}{l}\text { Takım } \\
\text { Oyunları, } \\
\text { Arkadaş } \\
\text { Oyunları }\end{array}$ & Arkadaş Oyunları & $\begin{array}{l}\text { Takım Oyunları, } \\
\text { Arkadaş Oyunları }\end{array}$ & $\begin{array}{c}\text { Bireysel, Arkadaş } \\
\text { Oyunları }\end{array}$ & $\begin{array}{l}\text { Takım Oyunları, } \\
\text { Arkadaş Oyunları }\end{array}$ & $\begin{array}{c}\text { Bireysel, Arkadaş } \\
\text { Oyunları }\end{array}$ & $\begin{array}{l}\text { Takım Oyunları, } \\
\text { Arkadaş Oyunları }\end{array}$ \\
\hline $\begin{array}{l}\text { Oyun } \\
\text { Arkadaşları }\end{array}$ & Komşular & $\begin{array}{l}\text { Komşu, } \\
\text { Kardeș }\end{array}$ & Komşular & Komşu, Kardeş & $\begin{array}{l}\text { Komşular, } \\
\text { kardeșler }\end{array}$ & $\begin{array}{l}\text { Komşular, } \\
\text { Kardeșler }\end{array}$ & Komşu, Kardeş & Komşu, Kardeş \\
\hline $\begin{array}{l}\text { Cinsiyet } \\
\text { Ayrımı }\end{array}$ & $\begin{array}{l}\text { Kadın } \\
\text { Erkek Ayrı }\end{array}$ & $\begin{array}{l}\text { Kadın Erkek } \\
\text { Birlikte }\end{array}$ & $\begin{array}{l}\text { Kadın Erkek } \\
\text { Birlikte }\end{array}$ & $\begin{array}{l}\text { Kadın Erkek } \\
\text { Birlikte }\end{array}$ & $\begin{array}{l}\text { Kadın Erkek, } \\
\text { Çoğunlukla Ayrı }\end{array}$ & $\begin{array}{l}\text { Kadın Erkek } \\
\text { Birlikte }\end{array}$ & $\begin{array}{c}\text { Kadın Erkek } \\
\text { Birlikte, } \\
\text { Çoğunlukla kadın } \\
\end{array}$ & $\begin{array}{c}\text { Çoğunlukla } \\
\text { Erkeklerle, Kadın } \\
\text { Erkek daha az } \\
\end{array}$ \\
\hline $\begin{array}{l}\text { Oyun } \\
\text { Materyali }\end{array}$ & $\begin{array}{c}\text { Taş, } \\
\text { Toprak, } \\
\text { Tahta }\end{array}$ & $\begin{array}{l}\text { Ağaç Dalı, } \\
\text { Sünger, } \\
\text { Tahta, Cam, } \\
\text { Boncuk, Tel } \\
\end{array}$ & Taş, Toprak, İp & $\begin{array}{c}\text { Ağaç Dalı, Sünger, } \\
\text { Tahta, Tel }\end{array}$ & $\begin{array}{l}\text { Taş, Toprak, Tahta, } \\
\text { kumass, kırık veya } \\
\text { eski kap kacak }\end{array}$ & $\begin{array}{c}\text { Ağaç Dalı, Tahta, } \\
\text { Cam, Boncuk, } \\
\text { Tel, }\end{array}$ & $\begin{array}{c}\text { Taş, Toprak, } \\
\text { Kumaș, İp, Boncuk, } \\
\text { Kap-Kacak }\end{array}$ & Ne Bulursak \\
\hline Oyun Tanımı & $\begin{array}{c}\text { Eğlence, } \\
\text { Çocukluğu } \\
\text { nu } \\
\text { Yaşamak }\end{array}$ & $\begin{array}{c}\text { Vakit } \\
\text { Geçirmek İçin } \\
\text { Eğlence }\end{array}$ & $\begin{array}{l}\text { Güç kazanmak, } \\
\text { Enerji atmak }\end{array}$ & Eğlence & Eğlence, & Eğlence, Keyif & $\begin{array}{l}\text { Eğlenmek, Zamanı } \\
\text { geçirmek }\end{array}$ & Eğlence \\
\hline
\end{tabular}


Tablo 3. Görüşmelerin özeti - çocuklar

\begin{tabular}{|c|c|c|c|c|c|c|c|c|}
\hline Değişken & Ç1 & Ç2 & Ç3 & Ç4 & Ç5 & Ç6 & Ç7 & Ç8 \\
\hline Cinsiyet & Kadın & Kadın & Kadın & Erkek & Erkek & Erkek & Erkek & Kadın \\
\hline Yaş & 9 & 11 & 14 & 9 & 12 & 15 & 16 & 11 \\
\hline Eğitim & $\begin{array}{c}\text { 3.Sinıf } \\
\text { Öğrencisi }\end{array}$ & 6. Sınıf Öğrencisi & $\begin{array}{l}\text { Lise1. Sinıf } \\
\text { Öğrencisi }\end{array}$ & $\begin{array}{l}\text { 3. Sinıf } \\
\text { Öğrencisi }\end{array}$ & 5. Sinıf & 9. Sinif & 10. Sinıf & 4. Sinif \\
\hline Oyun Yeri & $\begin{array}{c}\text { Sokak, Okul, } \\
\text { Park, Bahçe, } \\
\text { Ev } \\
\end{array}$ & $\begin{array}{l}\text { Sokak, Okul, } \\
\text { Park, }\end{array}$ & $\begin{array}{l}\text { Sokak, Okul, } \\
\text { Park, Bahçe, Ev }\end{array}$ & Sokak, Okul, & $\begin{array}{l}\text { Sokak, Okul, Park, } \\
\text { Bahçe, Ev }\end{array}$ & $\begin{array}{c}\text { Sokak, Okul, Park, } \\
\text { Oyun Salonları }\end{array}$ & $\begin{array}{l}\text { Sokak, Okul, } \\
\text { Oyun Salonu }\end{array}$ & $\begin{array}{l}\text { Sokak, Okul, Park, } \\
\text { Bahçe, Ev }\end{array}$ \\
\hline Oyun Türü & $\begin{array}{c}\text { Dijital } \\
\text { Oyunlar, } \\
\text { Arkadaş } \\
\text { Oyunları, } \\
\text { Takım } \\
\text { Oyunları, } \\
\text { Bireysel } \\
\text { Oyunlar }\end{array}$ & $\begin{array}{c}\text { Dijital Oyunlar, } \\
\text { Arkadaş } \\
\text { Oyunları, Takım } \\
\text { Oyunları, } \\
\text { Bireysel Oyunlar }\end{array}$ & $\begin{array}{l}\text { Dijital Oyunlar, } \\
\text { Arkadaş } \\
\text { Oyunları, Takım } \\
\text { Oyunları, } \\
\text { Bireysel } \\
\text { Oyunlar }\end{array}$ & $\begin{array}{l}\text { Dijital Oyunlar, } \\
\text { Arkadaş } \\
\text { Oyunları, Takım } \\
\text { Oyunları, } \\
\text { Bireysel } \\
\text { Oyunlar }\end{array}$ & $\begin{array}{c}\text { Dijital Oyunlar, } \\
\text { Arkadaş } \\
\text { Oyunları, Takım } \\
\text { Oyunları, Bireysel } \\
\text { Oyunlar }\end{array}$ & $\begin{array}{l}\text { Dijital Oyunlar, } \\
\text { Arkadaş Oyunları, } \\
\text { Takım Oyunları, } \\
\text { Bireysel Oyunlar }\end{array}$ & $\begin{array}{c}\text { Dijital Oyunlar, } \\
\text { Arkadaş } \\
\text { Oyunları, Takım } \\
\text { Oyunları, } \\
\text { Bireysel Oyunlar, }\end{array}$ & $\begin{array}{l}\text { Dijital Oyunlar, } \\
\text { Arkadaş Oyunları, } \\
\text { Takım Oyunları, } \\
\text { Bireysel Oyunlar }\end{array}$ \\
\hline $\begin{array}{l}\text { Oyun } \\
\text { Arkadaşları }\end{array}$ & $\begin{array}{c}\text { Komşu, } \\
\text { Arkadaş, } \\
\text { Okul } \\
\text { Arkadaşları, } \\
\text { Kardeș, } \\
\text { Anne-Baba } \\
\end{array}$ & $\begin{array}{l}\text { Komşu, Arkadaş, } \\
\text { Okul Arkadaşları }\end{array}$ & $\begin{array}{c}\text { Komşu, } \\
\text { Arkadaș, Okul } \\
\text { Arkadaşları, } \\
\text { Kardeş }\end{array}$ & $\begin{array}{c}\text { Komşu, } \\
\text { Arkadaş, Okul } \\
\text { Arkadaşları }\end{array}$ & $\begin{array}{l}\text { Komşu, Arkadaş, } \\
\text { Okul Arkadaşları, } \\
\text { Kardeş, Anne- } \\
\text { Baba, Sanal }\end{array}$ & $\begin{array}{l}\text { Komşu, Arkadaș, } \\
\text { Okul Arkadaşları, } \\
\text { Kardeş, Sanal }\end{array}$ & $\begin{array}{c}\text { Komşu, Arkadaş, } \\
\text { Okul Arkadaşları, } \\
\text { Sanal }\end{array}$ & $\begin{array}{c}\text { Komşu, Arkadaş, } \\
\text { Okul Arkadaşları, } \\
\text { Kardeş }\end{array}$ \\
\hline $\begin{array}{l}\text { Cinsiyet } \\
\text { Ayrımı }\end{array}$ & $\begin{array}{l}\text { Kadın Erkek } \\
\text { Birlikte }\end{array}$ & $\begin{array}{l}\text { Kadın Erkek } \\
\text { Birlikte }\end{array}$ & $\begin{array}{l}\text { Kadın Erkek } \\
\text { Birlikte }\end{array}$ & $\begin{array}{l}\text { Kadın Erkek } \\
\text { Birlikte }\end{array}$ & $\begin{array}{l}\text { Kadın Erkek } \\
\text { Birlikte }\end{array}$ & $\begin{array}{l}\text { Çoğunlukla } \\
\text { erkeklerle }\end{array}$ & $\begin{array}{l}\text { Kadın Erkek } \\
\text { Birlikte, } \\
\text { Çoğunlukla } \\
\text { Erkekler } \\
\end{array}$ & $\begin{array}{l}\text { Kadın Erkek Birlikte } \\
\text { ama Çoğunlukla } \\
\text { Kadınlar }\end{array}$ \\
\hline $\begin{array}{l}\text { Oyun } \\
\text { Materyali }\end{array}$ & $\begin{array}{l}\text { Toprak, } \\
\text { Yaprak, } \\
\text { Kağıt, Hazır } \\
\text { Oyuncaklar, } \\
\text { Bilgisayar }\end{array}$ & $\begin{array}{l}\text { Toprak, Taş, } \\
\text { Yaprak, Hazır } \\
\text { Oyuncaklar, } \\
\text { Telefon }\end{array}$ & $\begin{array}{l}\text { Toprak, Yaprak, } \\
\text { Kağıt, Hazır } \\
\text { Oyuncaklar, } \\
\text { Bilgisayar }\end{array}$ & $\begin{array}{l}\text { Toprak, Taş, } \\
\text { Yaprak, Hazır } \\
\text { Oyuncaklar, } \\
\text { Telefon }\end{array}$ & $\begin{array}{l}\text { Toprak, Yaprak, } \\
\text { Kağıt, Hazır } \\
\text { Oyuncaklar, } \\
\text { Bilgisayar }\end{array}$ & $\begin{array}{l}\text { Bilgisayar, Top, } \\
\text { Okey, Telefon }\end{array}$ & $\begin{array}{l}\text { Telefon, Tablet, } \\
\text { Oyun Aletleri, } \\
\text { Okey, İskambil }\end{array}$ & $\begin{array}{c}\text { Toprak, Yaprak, } \\
\text { Kağıt, Hazır } \\
\text { Oyuncaklar, Telefon- } \\
\text { Tablet }\end{array}$ \\
\hline Oyun Tanımı & Hayalgücü & Eğlence & $\begin{array}{l}\text { Hayalgücü, } \\
\text { Eğlence }\end{array}$ & Eğlence & Eğlence & Eğlence & $\begin{array}{c}\text { Eğlence, Boş } \\
\text { Zaman }\end{array}$ & $\begin{array}{l}\text { Eğlence, Arkadaş } \\
\text { Edinme }\end{array}$ \\
\hline
\end{tabular}


Ç5 de benzer șekilde, “... annem ve babamla da oyunlar oynuyoruz. İșten geldiklerinde ve yorgun olmadıklarında oynuyoruz. Hafta sonları daha çok oynuyoruz. Ben daha çok oynamak isterim ama zamanları olmuyor. Ben de bilgisayarda oyun oynuyorum..." demiștir. Burada șunu vurgulamak da fayda var, çocuklar büyüdükçe anne-babalarıyla oyun oynama ihtimalleri de düșmektedir. Ebeveynlerle oyunlar özellikle ilkokuldan sonra çok gözlemlenen durumlar değildir.

İki farklı kuşağın karşı cins ile birlikte oynama durumuna bakıldığı zaman sadece K1'de farklılașma görülmektedir. Katılımcının biyografisi incelendiği zaman aile ilișkileri burada önemli bir etken olarak görülmektedir. Katılımcı yetim kalmıș ve akrabalarının yanında büyümüştür. Erkeklerin oyun arkadaşı olarak tanımlanmamasında toplumsal normların etkili olduğu yorumuna buradan ulașılabilmektedir. Yaşlı bireylerin çocukluklarında kadın-erkek birlikte oyun oynayabildiklerine dair söylemlerinde, onların çocukluk algısının da önemli olduğunu belirtmek gerekir. Özellikle ergenliğe girme yaşı olarak 12-13 yaşları görülmektedir ve bu yașlardan itibaren kesinlikle kız ve erkek çocukları birlikte oyun oynayamamaktadır. Çünkü bu yaşlar yetişkinliğe geçiș olarak görülmekte bir nevi evlenme çağı olarak algılandığından kadın ve erkeklerin evli olmadan bir arada bulunmaları hoş karşılanmayan bir durum olarak kabul edilmektedir. Dolayısıyla görüşmeci yaşlı bireylerin çocukluktan anladıkları yaşların 12 yaştan öncesi olduğu bilinmelidir.

Bireylerin oyun materyalleri incelendiği zaman doğal materyaller ve hazır oyuncaklar olarak iki ayrı kategori öne çıkmaktadır. Doğal materyallerle bireyler kendileri oyuncak yaratmaktadırlar. K1 görüșme sırasında "Capıtları topladık renkli renkli çapıtları. Cöpü de böyle yaptık kol yaptık bacak yaptık. Onu bir süsledik allı yeșilli. Bir de hastalandım. Orda yaşlı bir adam vardı o bize türkü söyledi. Neydi türkü de aklımdaydı ama gelmiyor... Ben hastalandım ya gönlümü șen ediyor. Türküyü pek iyi biliyordum ya unuttum şuanda. Öyle bebekler yapardık hevesli hevesli. Onları kucă̆ımıza alırdık çöpü donatırdık giydirirdik" diyerek buna örnek vermiștir. Ayrıca günümüz çocukları da toprak, yaprak ve kağıt gibi materyallerle kendilerine oyuncaklar yapmakta olduklarını belirtmişlerdir. Bu durum Yeniköy'ün hala tam anlamıyla kentleșmemiș olmasından ve doğa ile iç içeliğini tamamen kaybetmemiş olmasından ileri gelmektedir. Fakat bunların yanında bilgisayar, telefon ve hazır oyuncaklar günümüzde teknolojinin gelişmesiyle birlikte çocukların oyun dünyasında daha fazla yer edinmiștir.

Bireylerin oyun tanımlarına bakıldığı zaman iki farklı tanımlama ön plana çıkmaktadır. Bunlardan ilki K1'in “... Oyun demek çocuk için ne demek çok zevkli bir şey demek. Gençliğini çocukluğunu yașıyorsun demek. Küçükken evlendim kızım. Ben yetim idim çocukluğumu yaşayamadım. Baba yok ana yok, dayı arasında büyüdüm..." ifadesidir. Burada yetim olmanın ve erken yaşta evlenmiş olmanın verdiği yarım kalma duygusu katılımcının oyun tanımlamasında önemli bir temeli oluşturmaktadır. Ayrıca Ç1'in tanımlamasında "Böyle... Hayal gücü demek... Hayallerimizi düşlerimizi gerçekleștirmeye yarıyor. ..." ifadesi çocukların oyunda kendi dünyalarını yarattığının bir göstergesi olarak kabul edilebilir niteliktedir. Yaşlı bireylerle çocuklar arasında bu açıdan pek fark bulunmamakla birlikte, çocuklar bos zaman etkinliği, hayal gücünü geliștirici etkinlik ve arkadaș bulma tanımlaması ile yaşlılardan ayrılmaktadır. Yaşlılarda bir kiși ise bugünden baktığında çocukluğunu yaşamak olarak tanımlayarak hem diğerlerinden hem de çocuklardan ayrılmaktadır.

\section{SONUÇ VE ÖNERILLER}

Araştırmada çıkan sonuçlar karşılaştırıldığında; oyun pratiklerinin temelde oyun oynanan yer, oyun türleri, oyun arkadașları, oyun materyalleri ve oyun tanımlamaları olarak farklılık gösterdiği görülmektedir. $\mathrm{Bu}$ farklılaşmanın temelinde katılımcıların aile yapıları, yaşanılan dönemin toplumsal normları, teknolojik gelişmelerin olduğu söylenebilir. Ayrıca Yeniköy özelinde bakıldığında oyun kültürünün geleneksel oyun kültüründen modern oyun kültürüne doğru evrilme sürecinde olduğu görülmektedir. Bunun sebepleri olarak da Yeniköy Mahallesi'nin kent merkezinin dışında kalmış olması, birincil ilișkilerin az da olsa devam ediyor olması, doğa ile iç içeliğinin hala devam ediyor olması ve bu nedenlerle çocukların hem teknolojiye hem de kırsal alanların verdiği doğal imkanlara ulaşmasının kolay olmasının etkili olduğu söylenebilir. Öte yandan eskiden oynanan bir çok oyunun bugün oynanmadığ ve hem kentleşme ve toplumsal değișme, hem de teknolojik gelișmeler karșısında yok olma gittiği veya yok olma riskiyle karşı karşıya olduğunu söylemek mümkündür.

Yeniköy özelinde yapılmış olan bu çalışmanın da göstermiş olduğu gibi, üniversitenin getirmiş olduğu kentleşme olgusu ve buna bağlı olarak ortaya çıkan toplumsal değișme, çocukların oyunları üzerinden bakıldığında da kendisini gösterebilmektedir. Her ne kadar teknoloji gelişmiş olsa da bugün kırsal yerleşim yerlerinde ve geleneksel mahalle havasını koruyan mekanlarda oyun alanı olarak sokaklar, parklar, bahçeler ve buralarda olan ağaçlar dahil her șey oyun alanı ve oyuncağın kendisi olabilmekte ve kimi zaman da oyuncaklar bu materyallerden üretilebilmektedir. Ancak Yeniköy bu özelliğinden hızla uzaklașmaktadır.

Kentleșme, ortaya çlktığı her alanda olduğu gibi Yeniköy'de de göç alımına ve göçle birlikte de toplumsal ilișkilerin, yerleșik köy kültürünün ve bunlara bağlı olarak da güvenlik algısının değişmesine neden olmaktadır. Bunun sonucu olarak (şimdilik - ki, bunun ileride değișme ihtimali de bulunmaktadır) yerlilerle dışarıdan gelenler arasında bir mesafe bulunmaktadır. Özellikle dışardan gelenler ya siteler şeklinde (özellikle bir pazarlama unsuru ve tercih olarak) güvenli alanlarda ya da kendi evlerini (kameralar, çitler vs. ile) güvenli hale getirerek sınırlar koymaktadır. Bu durum yerli halkın güvenlik anlayıșına da ister istemez yansımakta, kaynaşmayl, ortak bir oyun kültürü geliştirmeyi önlemekte ve var olan kültürün de yavaş yavaş kaybolmasına sebep olmaktadır. Yine buna bağlı olarak çocuklar ev-okul merkezli oyunlara dönmekte, teknolojinin sunduğu imkanları da sonuna kadar kullanarak bireysel ve teknolojik sanal oyunlara yönelmektedir. Bu durumun 
sonucu olarak oyunlar da bireyselleşmekte, grup oyunlarından, doğadan, geleneksel olandan uzaklașıp standart yapay, bireysel veya daha az grupsal ve teknolojik oyunlara dönüşmektedir. Çocuklar için bu durumun yarattığı en önemli sıkıntılardan birisi ise geçmişle bağlantılarının kopması ve sadece bugünün koșullarının ürettiği ve dayattığı oyunlara mahkum kalmalarıdır.

Köye özgü üretim biçimleri de kentleşmeyle birlikte hızla değiștiğinden, özellikle kadınlar da yeni işlerde çalışmaya yönelmektedirler. Bu durum çocukların sokakta oyun oynayabilme ihtimallerini azaltmakta, aileler yaşadıkları güvenlik kaygısı nedeniyle evbahçe-okul alanı dışında kalan alanlarda çocuklarının oyun oynamasını daha az güvenli bulabilmektedirler. Böylelikle geçmişten gelen oyun kültürü de hızla değişmektedir. Özellikle Yeniköy geçmişte yoğun olarak tütün tarımı ve hayvancılıkla (Yörük köyü olduğundan ağırlık olarak keçi) uğraşan köylüler, bu işlerle uğraşırken çocuklarını da yanlarına alıp yazları yaylalara göç etmekteydiler. Bu etkinlikler sürecinde çocukların oyun alanları tümüyle doğa, araçları doğal olan her șey ve hayvanlar olabiliyordu. Ancak bugün kentleşme bu durumu tamamen ortadan kaldırmış, tütün ekilen tarım alanları yapılaşmaya açılmıș, hayvancılık ise üç-beş ailenin yerleșim alanları dışında yaptığı sınırlı bir ekonomik faaliyete dönüşmüştür.

Geleneksel üretim biçimi ve toplumsal ilişskilerin olduğu dönemlerde yaşlı bireylerin bir işlevi de çocuklarla oyunlar oynamak, onlara bakmak ve onların korunması-kollanması ile yakından ilgilenmektir. Araştırma sahasındaki durum gözlemlendiğinde bu işlevin de artık yitirilmeye yüz tuttuğu görülmüștür. Bunun en önemli sebebi toplumsal değișmenin bir sonucu olarak çekirdek aileye dönülmüş olmasıdır. Diğer sebep ise, çocukların mutlaka iyi bir okula gidebilmek içinde ders dişı zamanlarda kurslara veya etütlere gitmelerinin zorunluluk haline getirilmiş olmasıdır.

Yeniköy Mahallesi'nde yaşanan ve Türkiye'deki göç, kentleşme, sosyal değişme ve teknoloji bağlantılı bu sorunun çözümünde en etkili önlem tarımsal alanların, hayvansal üretim yapılan meraların yapılaşmaya açılmasının engellenmesidir. Yoğun şekilde gelen göçle oluşan nüfus baskısı, yerel halkın hemen yakındaki Kötekli Mahallesi'nde olduğu gibi yüksek binalar, apartlar yaparak üretimden uzak bir rant geliri ile yașamlarını sürdürme arzusu desteklenmemelidir. Çünkü, sorun sadece geleneksel kültürün ve buna bağlı oyun kültürünün yok olması değil, aynı zamanda verimli tarım alanlarının yok edilerek tarımsal ve hayvansal üretimin büyük oranda düşüş sağlamasıdır. Betonla mühürlenen tarım alanlarının bir daha geri dönüșü mümkün olamamakta, artan nüfusun alt yapı ve özellikle su ihtiyaçları mevcut koşullarda karşılanamamaktadır.

\section{ÇIKAR ÇATIŞMASI}

Yazarlar tarafından herhangi bir çıkar çatışması beyan edilmemiştir.

\section{KAYNAKÇA}

Akçay, D., \& Özcebe, H. (2012). Okul öncesi eğitim alan çocukların ve ailelerinin bilgisayar oyunu oynama alışkanlıklarının değerlendirilmesi. Cocuk Dergisi, 12(2), 66-71.

Akınbay, H. (2014). Okul Öncesi Dönemde Oyunun Önemi ve Cocukların Motor Gelișimi Üzerine Etkileri. (Yayımlanmamış Yüksek Lisans Tezi). Selçuk Üniversitesi, Konya.

Arslan, F. (2000). 1-3 Yaş Dönemindeki Cocuğun Oyun ve Oyuncak Özelliklerinin Gelișim Kuramları ile Açıklanması. C.Ü. Hemşirelik Yüksek Okulu Dergisi, 4(2), 40-43.

Büyüköztürk, Ş., Kılıç Çakmak, E., Akgün, Ö. E., Karadeniz, S., \& Demirel, F. (2014). Bilimsel Araştırma Yöntemleri. Ankara: Pegem Yayınevi.

Cinel, N. Ö. (2006). Farklı Sosyo-Ekonomik Düzeydeki 3-6 Yaş Grubu Cocuğu Olan Anne Babaların Oyuncak ve Oyun Materyalleri Hakkındaki Görüșlerinin ve Bu Yaș Grubu Cocukların Sahip Oldukları Oyuncak ve Oyun Materyallerinin Incelenmesi. (Yayımlanmamış Yüksek Lisans Tezi). Gazi Üniversitesi, Ankara.

Çelebi, N. (2007). Sosyoloji Notları. Ankara: Anı Yayıncılık.

Sormaz, F. (2010). Cocukluk Imgesi, Oyun ve Oyuncak: Sosyo-kültürel Bir Analiz. (Yayımlanmamıș Yüksek Lisans Tezi). Dumlupınar Üniversitesi, Kütahya, Türkiye.

Şahinkaya, R. (2008). Cocuk Psikolojisi. Ankara: Ankara Üniversitesi Basımevi.

Tolan, B. (2005). Sosyoloji. Ankara: Gazi Kitabevi.

Uluğ, M. (2007). Niçin Oyun? İstanbul: Anfora Yayıncılık. 